\title{
Enamel Carious Lesion Development in Response to Sucrose and Fluoride Concentrations and to Time of Biofilm Formation: An Artificial-Mouth Study
}

\author{
Rodrigo Alex Arthur, ${ }^{1}$ Eduardo Kazuo Kohara, ${ }^{2}$ Robert Aaron Waeiss, ${ }^{2}$ \\ George J. Eckert, ${ }^{3}$ Domenick Zero, ${ }^{2}$ and Masatoshi Ando ${ }^{2}$ \\ ${ }^{1}$ Faculty of Dentistry, Federal University of Rio Grande do Sul, Rua Ramiro Barcelos 2492, 90035-003 Porto Alegre, RS, Brazil \\ ${ }^{2}$ Oral Health Research Institute, Indiana School of Dentistry, 415 Lansing Street, Indianapolis, IN 46202, USA \\ ${ }^{3}$ Department of Biostatistics, Indiana School of Medicine, 410 W. Tenth Street, Suite 3000, Indianapolis, IN 46202, USA
}

Correspondence should be addressed to Rodrigo Alex Arthur; rodrigoarthur.ufrgs@gmail.com

Received 27 April 2014; Accepted 3 September 2014; Published 15 September 2014

Academic Editor: Tarek El-Bialy

Copyright ( 92014 Rodrigo Alex Arthur et al. This is an open access article distributed under the Creative Commons Attribution License, which permits unrestricted use, distribution, and reproduction in any medium, provided the original work is properly cited.

\begin{abstract}
The aim of this study was to evaluate both sucrose and fluoride concentrations and time of biofilm formation on enamel carious lesions induced by an in vitro artificial-mouth caries model. For Study 1, biofilms formed by streptococci and lactobacilli were grown on the surface of human enamel slabs and exposed to artificial saliva containing 0.50 or $0.75 \mathrm{ppmF}(22.5 \mathrm{~h} / \mathrm{d})$ and broth containing 3 or $5 \%$ sucrose ( $30 \mathrm{~min} ; 3 \mathrm{x} / \mathrm{d}$ ) over $5 \mathrm{~d}$. In Study 2, biofilms were grown in the presence of $0.75 \mathrm{ppmF}$ and $3 \%$ sucrose over 3 and 9 days. Counts of viable cells on biofilms, lesion depth (LD), and the integrated mineral loss (IML) on enamel specimens were assessed at the end of the tested conditions. Counts of total viable cells and L. casei were affected by sucrose and fluoride concentrations as well as by time of biofilm formation. Enamel carious lesions were shallower and IML was lower in the presence of $0.75 \mathrm{ppmF}$ than in the presence of $0.50 \mathrm{ppmF}(P<0.005)$. No significant effect of sucrose concentrations was found with respect to LD and IML $(P>0.25)$. Additionally, deeper lesions and higher IML were found after $9 \mathrm{~d}$ of biofilm formation $(P<0.005)$. Distinct sucrose concentrations did not affect enamel carious lesion development. The severity of enamel demineralization was reduced by the presence of the higher fluoride concentration. Additionally, an increase in the time of biofilm formation produced greater demineralization. Our results also suggest that the present model is suitable for studying aspects related to caries lesion development.
\end{abstract}

\section{Introduction}

Supragingival dental biofilm is a multispecies community of microorganisms embedded in a matrix attached to dental surfaces. Its accumulation on teeth is a necessary factor for occurrence of dental caries, which is considered to be a disease resulting from the sum of complex interactions among tooth structure, supragingival biofilm, diet, time, and other oral and personal factors [1]. This disease is related to frequent ingestion of rapidly fermentable carbohydrates that are converted to acid-end products by bacterial metabolism. The acidic $\mathrm{pH}$ produced due to fermentation of dietary carbohydrates induces ecological changes in dental biofilm. Acidtolerant bacteria that are normal constituents of the oral microbiota, but present at low levels, have increased proportions in response to acidic environmental conditions [2]. These bacteria continue to produce acids, extending the time in which the biofilm remains at low $\mathrm{pH}$ levels. Additionally, the low $\mathrm{pH}$ produced as the result of this process disrupts the mineral equilibrium between enamel and the surroundings, leading to dental demineralization [3].

Besides the above induced ecological changes, the low $\mathrm{pH}$ environment on dental biofilm makes the biofilm fluid undersaturated with respect to the tooth mineral (hydroxyapatitelike mineral). Under this condition of $\mathrm{pH}$ lower than 5.5, hydroxyapatite dissolves and a demineralization process occurs [4]. However, when fluoride is continuously available in the biofilm fluid, a condition achieved under daily 
consumption of optimal fluoridated water or under the regular use of fluoridated dentifrices [5], and in a condition of a $\mathrm{pH}$ not lower than 4.5 , hydroxyapatite is dissolved but at the same time a less soluble mineral (a fluorapatite-like mineral) is formed on tooth surface resulting in a lower net mineral loss [6]. Therefore, fluoride modifies the balance between demineralization and remineralization processes, inhibiting the former and promoting the latter [6]. As a consequence of this long-term physicochemical effect, a reduction in caries progression might be expected [7]. In this context, it is clear that fluoride plays a key role in the prevention and control of this disease $[8,9]$.

Among the fermentable carbohydrates, sucrose is considered the most cariogenic: it is the unique substrate necessary for synthesis of insoluble extracellular polysaccharides [10] that increase the thickness and porosity of biofilms [11] and lead to a deeper $\mathrm{pH}$ fall on the tooth-dental biofilm interface [12]. In addition, dental biofilm formed in the presence of sucrose has lower inorganic concentration [13] and altered protein expression [14], which could also contribute to its enhanced cariogenicity.

In vitro biofilm caries models have been widely used to study the carious process under laboratorial controlled conditions, in an attempt to simulate the clinical development of carious lesions [15-19]. These models differ among them mainly regarding the source of bacteria used to form the biofilm and regarding the dynamic of carbohydrate/fluoride exposures during carious lesions development. Whereas monospecies biofilm models based only on cultivation of Streptococcus mutans $[16,17]$ do not mimic the metabolic interactions that occur among the diverse microbiota of a clinical dental biofilm, the outcomes obtained by highcomplexity microbial models based on microcosm cultivation are directly dependent on inoculum source $[18,19]$. On the other hand, multispecies biofilms models based on the cultivation of specific microorganisms might create a more controlled and less variable condition for carious lesions development. Therefore, an in vitro artificial-mouth multispecies microbial model was developed to create incipient carious lesions on enamel specimens induced by commensals and known cariogenic bacteria [20]. That model presents the advantage of simulating the feast and famine episodes present in the oral cavity since the carbohydrates are provided to the biofilm only for short periods of time mimicking the three main meals a subject may have per day in a clinical condition. Moreover, that model also simulates the clearance promoted by salivary flow since an artificial saliva solution continuously washes the biofilm, contributing to the removal of weak adherent bacteria and to the removal of chemicals produced by the biofilm. Additionally, enamel carious lesions are generated as a result of the intricate metabolic interactions among the biofilm microbial components which represent a clinical condition of dental biofilm growth. Since sucrose and fluoride have played a major role on demineralization/ remineralization phenomena, we aimed to evaluate the effects of these factors under well-controlled conditions on enamel lesion development generated by that artificial-mouth model. Additionally, we also sought to investigate the progression of enamel lesions in response to time of biofilm formation.
Considering the similarities between the abovementioned artificial-mouth and clinical conditions, we hypothesize that this model is suitable for studying aspects related to caries lesion development and progression. It could be used as a feasible alternative to in vivo and clinical studies.

\section{Material and Methods}

The use of human teeth was approved by the Indiana University-Purdue University at Indianapolis (IUPUI) Institutional Review Board (IRB) number 0306-64.

2.1. Experimental Design. The study consisted of 2 experiments. Study 1 evaluated the effect of sucrose at $3 \%$ and $5 \%$ in addition to the fluoride concentrations of $0.50 \mathrm{ppm}$ and $0.75 \mathrm{ppm}$ on enamel carious lesions produced during $5 \mathrm{~d}$ by multispecies microbial consortia. Study 2 evaluated the effect that exposure of enamel slabs to microbial biofilms for 3 and $9 \mathrm{~d}$ had on enamel carious lesion progression. The two studies resulted in a total of 6 experimental groups. For each study, seven enamel slabs were randomly assigned to each experimental group and demineralized using a multispecies microbial model for enamel caries lesion formation. At the end of each experimental period, the slabs were analyzed via transversal microradiography to calculate lesion depth and integrated mineral loss.

2.2. Specimen Preparation. Forty-two human enamel slabs $(3 \mathrm{~mm} \times 3 \mathrm{~mm} \times 2 \mathrm{~mm})$ were obtained from middle third of buccal surfaces of human incisors. Pulpal surfaces of the slabs were flattened in a grinding machine (RotoPol31/RotoForce 4 polishing unit; Struers, Cleveland, OH, USA) with 500-grit silicon carbide grinding paper. Enamel surfaces were polished to a mirror-like finish with 1200,2400 , and 4000-grit grinding paper and then by a polishing cloth with a $1 \mu \mathrm{m}$ diamond suspension (DP Suspension, Struers A/S, Denmark) [21, 22]. Specimens with any cracks or scratches were discarded. Selected slabs showed at least $1.0 \mathrm{~mm}$ depth of exposed enamel. The enamel surface of each slab was covered with nail varnish, leaving only a $2 \mathrm{~mm} \times 1 \mathrm{~mm}$ uncovered window to standardize the enamel area to be demineralized. Each prepared slab was attached to one end of a Plexiglass acrylic rod (10 mm length and $7 \mathrm{~mm}$ diameter) with double sided tape and sticky wax. The slabs were randomly assigned to experimental groups ( $n=7$ /group). The other end of the Plexiglass rods was attached to a Plexiglass round platform with cyanoacrylate adhesive (Super Glue, Loctite Corp., USA) as described elsewhere [23]. Rods, platforms, and slabs were sterilized with ethylene oxide gas at $55^{\circ} \mathrm{C}$ for $1 \mathrm{~h}$ prior to microbial inoculation.

2.3. In Vitro Formation of Enamel Carious Lesions. Enamel carious lesions were produced using a multispecies microbial model for caries formation developed by Fontana et al. [20, 23] with modifications.

2.3.1. Inoculum Preparation. For biofilm formation, the following species were used: Actinomyces naeslundii (ATCC 
19039), Lactobacillus casei (ATCC 4646), Streptococcus mutans (UA 159), Streptococcus salivarius (ATCC 25975), and Streptococcus sanguinis (BAA-1455) [20]. The strains were cultivated on Columbia Blood Agar (CBA; Difco, Sparks, $\mathrm{MD}$, USA). Colony-forming units (CFU) were individually transferred from CBA plates to tubes containing Tryptic Soy Broth (TSB) supplemented with $1 \%$ sucrose and incubated at $37^{\circ} \mathrm{C}$ with $5 \% \mathrm{CO}_{2}$. After $18 \mathrm{~h}$ of incubation, aliquots of each suspension were individually transferred to fresh TSB supplemented with $1 \%$ sucrose and further incubated until optical density of $1.0 \pm 0.1$ at $550 \mathrm{~nm}$ [24]. Aliquots of each strain were then combined to form multispecies microbial consortia.

2.3.2. Enamel Demineralization. Prior to microbial consortia inoculation, each platform containing the acrylic rods and enamel slabs was individually transferred to sterile $125 \mathrm{~mL}$ stirring vessel (Pyrex, Fisher). All slabs were coated with $20 \mu \mathrm{L}$ of filter-sterilized pooled saliva for $20 \mathrm{~min}$. The preparation of saliva was described elsewhere [20]. Saliva was obtained from healthy donors. Six volunteers (18 to 50 years old) who fulfilled the inclusion criteria (mean stimulated saliva flow rate $\geq 0.7 \mathrm{~mL} / \mathrm{min}$ ) and exclusion criteria (antibiotics use for the last two months, use of any medication that modifies salivary secretion, periodontal disease, and general systemic illness) donate whole stimulated saliva. The study protocol was approved by the IUPUI Institutional Review Board (IRB 0304-58). A written consent was obtained from volunteers prior to saliva collection at the Oral Health Research Institute of Indiana University School of Dentistry. The saliva samples were pooled and centrifuged and the supernatant filter was sterilized $(0.22 \mu \mathrm{m}$ general purpose filter system, Corning, NY, USA). After salivary pellicle formation, the slabs were inoculated with $20 \mu \mathrm{L}$ of the multispecies microbial consortia and incubated for $2 \mathrm{~h}$ to allow bacterial adhesion with the enamel. Two independent lengths of silicone tubing $(\mathrm{ID}=1 / 8 \mathrm{inch}, \mathrm{OD}=1 / 4$ inch, wall thickness = 1/16 inch; PharmTubing) were attached to each stirring vessel, providing the Mineral Wash solution ( $\mathrm{MW} ; \mathrm{KCl}$ $83 \mathrm{mM}$; $\mathrm{NaCl} 148 \mathrm{mM} ; \mathrm{KH}_{2} \mathrm{PO}_{4} 0.02 \mathrm{mM} ; \mathrm{MgCl}_{2} 0.06 \mathrm{mM}$; and $\mathrm{CaCl}_{2} \quad 14 \mathrm{mM}$ ) and TSB supplemented with sucrose at the flow of $0.7 \mathrm{~mL} / \mathrm{min}$ using peristaltic pumps (Wiz peristaltic pump; ISCO, Inc., Lincoln, NE, USA). The fluid of each stirring vessel was continuously collected by drainage tubing at $0.7 \mathrm{~mL} / \mathrm{min}$ and transferred to a separate container. Vessels were placed on an electrical stirrer and kept at $37^{\circ} \mathrm{C}$. $\mathrm{MW}$ and TSB bottles were also kept at $37^{\circ} \mathrm{C}$ [23].

2.3.3. Study 1. Enamel carious lesions were produced on slabs ( $n=7$ /group) over $5 \mathrm{~d}$ of exposure to TSB supplemented with sucrose $3 \%$ or $5 \%$ and MW supplemented with $0.50 \mathrm{ppmF}$ or $0.75 \mathrm{ppmF}$. Throughout the study, a feast and famine protocol was adopted where TSB was dispensed to the stirring vessels 3 times a day for $30 \mathrm{~min}$ each and MW was dispensed during the remaining time $(22.5 \mathrm{~h})$ [20]. The $\mathrm{pH}$, bacteria viability, and lack of contamination were recorded at $2 \mathrm{~d}$ intervals from the fluid collected in the drainage containers. The $\mathrm{pH}$ of $\mathrm{MW}$, $\mathrm{TSB}$, and the circulating fluid of stirring vessels was checked at the end of each experimental test. Aliquots of the circulating fluid were also collected and examined for lack of contamination at the end of each test period.

2.3.4. Study 2. Enamel carious lesions were produced on slabs ( $n=7$ /group) over 3 and $9 \mathrm{~d}$ under exposure to TSB supplemented with $3 \%$ sucrose and MW supplemented with $0.75 \mathrm{ppmF}$. The same feast and famine protocol described above was adopted for this study. Bacteria viability, $\mathrm{pH}$, and lack of contamination were checked as well.

2.3.5. Harvesting of Microbial Biofilms and Determination of Counts of Viable Cells. After $5 \mathrm{~d}$ (Study 1) or 3 or $9 \mathrm{~d}$ (Study 2) of biofilm formation, enamel slabs were removed from the acrylic rods and individually transferred to tubes containing $1 \mathrm{~mL}$ of sterile $0.9 \% \mathrm{NaCl}$. The biofilm suspension was vortexed for $30 \mathrm{~s}$ and sonicated at $7 \mathrm{~W}$ for $30 \mathrm{~s}$ before aliquots were inoculated on CBA plates (for counts of total bacteria, A. naeslundii, S. mutans, S. salivarius, and S. sanguinis) and Rogosa SL agar (for counts of $L$. casei) using the spiral plate method. Plates were incubated at $37^{\circ} \mathrm{C}$ for $48 \mathrm{~h}$ under $5 \%$ $\mathrm{pCO}_{2}$. CFU were then counted using a stereomicroscope and the results were expressed as CFU/mL.

2.4. Transversal Microradiography (TMR) Assessment. After demineralization, approximately $100 \mu \mathrm{m}$ thick slices were obtained from the center of the demineralized area with a hard tissue microtome (Scientific Fabrications Laboratory, Lafayette, CO, USA). Each slice had sound and demineralized areas that corresponded to those covered and not covered by nail varnish, respectively. Slices were mounted together with an aluminum step wedge on X-ray glass plates (High Resolution UF Plate, Microchrome Technology, Inc., CA, USA) and exposed to $\mathrm{Cu}(\mathrm{K} \alpha) \mathrm{X}$-rays at $20 \mathrm{kV}$ and $30 \mathrm{~mA}$ for $65 \mathrm{~min}$ [22]. Glass plates were developed in a conventional way and examined with a customized computer program (TMR for Windows 2006-Inspektor Research Systems BV, The Netherlands). Lesion depth (LD; $\mu \mathrm{m})$ and integrated mineral loss (IML; vol\% mineral $\times \mu \mathrm{m}$ ) were determined as described by Ando et al. [25].

2.5. Statistical Analysis. Comparisons between groups were made using Wilcoxon Rank Sum tests. All analyses were performed using SAS, version 9.3 (SAS Institute, Inc., Cary, NC).

\section{Results}

Overall, the $\mathrm{pH}$ of the fluid collected from drainage containers ranged from 4.0 to 4.3 for all tested conditions. The $\mathrm{pH}$ of TSB and MW was around 7.0-7.2 showing absence of contamination. Additionally, no contamination was found throughout the study. This was verified by plating aliquots of drainage containers and stirring vessels on CBA plates where counts of viable cells ranged from $10^{6}$ to $10^{7} \mathrm{CFU} / \mathrm{mL}$. Regarding counts of total viable cells on biofilms, about $10^{8} \mathrm{CFU} / \mathrm{mL}$ was found in each condition. L. casei was the most prevalent strain followed by $S$. salivarius. Counts of viable cells of the other 
TABLE 1: Counts of viable cells on biofilms (CFU/mL), IML, and LD (mean $\pm \mathrm{sd}$ ) of enamel slabs after $5 \mathrm{~d}$ of biofilm formation according to fluoride and sucrose concentrations.

\begin{tabular}{|c|c|c|c|c|}
\hline \multirow{2}{*}{$\begin{array}{l}\text { Variables } \\
(n=7)\end{array}$} & \multicolumn{2}{|c|}{$0.50 \mathrm{ppmF}$} & \multicolumn{2}{|c|}{$0.75 \mathrm{ppmF}$} \\
\hline & $3 \%$ sucrose & $5 \%$ sucrose & $3 \%$ sucrose & $5 \%$ sucrose \\
\hline Total cells $\left(\times 10^{8}\right)$ & $0.9 \pm 0.4^{\mathrm{b}}$ & $1.4 \pm 0.2^{\mathrm{a}}$ & $1.1 \pm 0.2^{\mathrm{ab}}$ & $1.3 \pm 0.5^{\mathrm{ab}}$ \\
\hline L. casei $\left(\times 10^{8}\right)$ & $1.0 \pm 0.3^{b}$ & $1.5 \pm 0.2^{\mathrm{a}}$ & $1.1 \pm 0.2^{\mathrm{b}}$ & $1.3 \pm 0.5^{\mathrm{ab}}$ \\
\hline S. salivarius $\left(\times 10^{5}\right)$ & $1.4 \pm 1.3^{\mathrm{a}}$ & $0.6 \pm 0.4^{\mathrm{a}}$ & $0.9 \pm 0.6^{\mathrm{a}}$ & $1.2 \pm 0.8^{\mathrm{a}}$ \\
\hline IML $(\operatorname{vol} \% \times \mu \mathrm{m})$ & $2252 \pm 341^{\mathrm{a}}$ & $2484 \pm 311^{\mathrm{a}}$ & $1501 \pm 279^{b}$ & $1544 \pm 105^{\mathrm{b}}$ \\
\hline $\mathrm{LD}(\mu \mathrm{m})$ & $71.3 \pm 3.8^{\mathrm{a}}$ & $70.1 \pm 11.4^{\mathrm{a}}$ & $48.6 \pm 10.6^{\mathrm{b}}$ & $48.7 \pm 2.5^{\mathrm{b}}$ \\
\hline
\end{tabular}

Means followed by distinct letters differ statistically $(P<0.05)$.

strains were below the detection limit. With respect to demineralization, subsurface lesions were developed on most of the enamel slabs with a surface layer more mineralized than the body of the lesion.

3.1. Study 1. The resting $\mathrm{pH}$ of vessels containing groups exposed to 0.50 ppmF was lower at 4.36 and 4.0 for 3 and $5 \%$ sucrose than those of groups exposed to $0.75 \mathrm{ppmF}$ at 4.66 and 5.03 for 3 and $5 \%$, respectively. In the presence of $0.50 \mathrm{ppmF}$, counts of total viable cells and L. casei found in biofilms were statistically higher under exposure to $5 \%$ sucrose than those found under 3\% sucrose $(P<0.05)$ (Table 1). No significant differences in CFU were found between $3 \%$ and $5 \%$ sucrose in the presence of $0.75 \mathrm{ppmF}$. No differences were found in relation to counts of $S$. salivarius in biofilms. With respect to enamel carious lesion formation, the comparisons showed lower LD and lower IML in the presence of $0.75 \mathrm{ppmF}(P<0.05)$ (Table 1$)$. Signs of enamel surface wear were found on slabs exposed to $5 \%$ sucrose and $0.50 \mathrm{ppmF}$. Additionally, no statistically significant differences were found on lesion formation regarding sucrose concentration (Table 1).

3.2. Study 2. Based on results of Study 1, $0.75 \mathrm{ppmF}$ and $3 \%$ sucrose were the conditions adopted for Study 2 . The resting $\mathrm{pH}$ of the vessels after 3 and $9 \mathrm{~d}$ of biofilm growth was 4.92 and 5.07 , respectively. Counts of total viable cells and $L$. casei were statistically higher after $9 \mathrm{~d}$ of biofilm growth than after $3 \mathrm{~d}$ $(P<0.05)$. No differences were found for $S$. salivarius counts. LD and IML were approximately two times higher on enamel slabs after $9 \mathrm{~d}$ compared to $3 \mathrm{~d}$ of exposure to the microbial model $(P<0.05)$ (Table 2$)$.

When the data of Study 2 for 3 and $9 \mathrm{~d}$ exposure were compared to the corresponding group from Study 1 (5 days; 0.75 ppmF and 3\% sucrose), counts of total viable cells and $L$. case $i$ were statistically lower for $3 \mathrm{~d}$ than $5 \mathrm{~d}(P=0.0103)$ and no statistical difference was found between 5 and $9 \mathrm{~d}$. With respect to demineralization, IML and $\mathrm{LD}$ were statistically higher for $9 \mathrm{~d}$ compared to $5 \mathrm{~d}(P=0.0034)$, which was not different compared to $3 \mathrm{~d}$.

\section{Discussion}

As expected, the results of Study 1 clearly show the effect of fluoride in the enamel carious lesion inhibition (Table 1).
After $5 \mathrm{~d}$ of undisturbed biofilm formation, there was a decrease of up to $30-40 \%$ in mineral loss and lesion depth of enamel slabs in the presence of the higher fluoride concentration $(0.75 \mathrm{ppm})$, irrespective of the sucrose concentration (Table 1). Physicochemically, in the presence of fluoride, fluorapatite is precipitated on the surface of enamel and decreases the net mineral loss [26]. Higher fluoride concentrations are associated with a higher saturation with respect to fluorapatite and more mineral forms precipitate on the enamel surface. This property might explain the reduced lesion depth found in slabs exposed to the higher fluoride concentration. In this scenario, a subsuperficial and shallower lesion is developed. The effect of a lower fluoride concentration $(0.25 \mathrm{ppm})$ added to the MW on enamel demineralization was tested but generated a majority of specimens with surface loss (data not shown). Under the current conditions, surface wear was found on slabs exposed to $5 \%$ sucrose and $0.50 \mathrm{ppmF}$. Within this group, one had a completely eroded surface. No signs of enamel surface wear were found on slabs under the other tested conditions.

Under our experimental conditions, there was no statistical difference in enamel carious lesion development in relation to the tested sucrose concentrations (Table 1). However, previous data from an in situ study have shown a statistically significant increase in mineral loss of enamel slabs exposed to $5 \%$ sucrose compared with those exposed to $1 \%$ sucrose [27]. The same trend was also observed by a shortterm study using artificial biofilm [28]. The differences found between our data and those of Aires et al. [27] might be related mainly to the fact that in the latter study sucrose was provided to the in situ formed biofilms in a frequency of $8 \mathrm{x}$ /day during 14 days whereas the cariogenic challenge in our study was induced only three times a day during 5 days only. Additionally, the absence of a sucrose concentration effect on carious lesion development found in our study might be also attributed to the close tested concentrations.

In an attempt to avoid enamel surface wear, we chose the lower sucrose concentration (3\%) and the higher fluoride concentration $(0.75 \mathrm{ppm})$ to evaluate the progression of the lesions under 3 and $9 \mathrm{~d}$ of undisturbed in vitro biofilm formation. Previous unpublished data of our research group suggested that the exposure of in vitro biofilms to sucrose concentration higher than 5\% induces a strong cariogenic challenge able to cause enamel surface wear. Therefore, the rationale behind the chosen sucrose and fluoride concentrations used in this study was to allow enamel demineralization 
without losing the surface integrity because it could compromise any assessment of lesions progression. Since this model has been designed to simulate clinical conditions, carious lesions must be created in a standardized way. In this respect, in response to the chosen concentrations, early stages of enamel carious lesions were able to be created.

In Study 2, as expected, the longer the length of exposure of enamel slabs to microbial biofilms, the deeper the lesions and the higher the mineral loss. Overall, no signs of surface wear were found on the slabs in the course of $9 \mathrm{~d}$ of biofilm growth. However, enamel surface wear was found when enamel specimens were exposed to undisturbed biofilms for periods longer than $9 \mathrm{~d}$ (unpublished data of our research group). Under our experimental conditions, enamel slabs lost about two times more mineral content and the lesions were two times deeper after $9 \mathrm{~d}$ of undisturbed biofilm formation than those found on slabs exposed for $3 \mathrm{~d}$ to undisturbed biofilm formation (Table 2). The same trend was found by Fontana et al. [20] on enamel slabs exposed to undisturbed biofilm formation from 2 and up to $8 \mathrm{~d}$. However, the extent of mineral loss was not similar in these two experiments due to differences in biofilm microbial composition and fluoride concentration in the MW.

The comparison between microbiological and demineralization data among 3,5, and $9 \mathrm{~d}$ suggested that a microbial transition occurred during the first $5 \mathrm{~d}$ of biofilm growth. This is demonstrated by higher counts of viable cells than those found on $3 \mathrm{~d}$ but not different compared to those of $9 \mathrm{~d}$. S. salivarius counts were not affected by time of biofilm formation; however, counts of $L$. casei were higher after $5 \mathrm{~d}$ of biofilm formation (Table 2). Although the experimental conditions are different compared to those of the present study, a maturation of microbial composition of biofilm was also found by Fontana et al. [20] after $5 \mathrm{~d}$ of biofilm formation. We hypothesize that metabolic changes that might have occurred in biofilms during their maturation process could be one of the factors responsible for the highest cariogenicity found after $9 \mathrm{~d}$.

In the present study, enamel carious lesions had about $80 \mu \mathrm{m}$ of depth after $9 \mathrm{~d}$ of undisrupted biofilm formation (Table 2). Clinically, this is similar to the depth of an enamel carious lesion developed in vivo after 4 wk on teeth surrounded by orthodontic bands and submitted to dental biofilm accumulation $[29,30]$. The advantages of clinical in vivo models or clinical trials for caries development are that the progression of the lesion can be studied in vital teeth [31] and lesions are developed in the human mouth as a result of the interaction among subject's microbiota, diet, salivary flow, and salivary buffer capacity. However, in vivo studies are expensive and time-consuming. Additionally, the interindividual variation might influence outcomes and interpretation of results and the experiment can be performed only once in each subject [31]. In this context, despite the limitations of the present artificial-mouth model, pointed out by Fontana et al. [23], our data suggest that this model may be used as a promising alternative to in vivo models to study enamel carious lesion development and progression. We do believe it is important to have a model whose features are close to a real clinical condition. Therefore, it would be ideal to simulate the
TABLE 2: Counts of viable cells on biofilms (CFU/mL), IML, and LD (mean $\pm \mathrm{sd}$ ) of enamel slabs after 3 and $9 \mathrm{~d}$ of biofilm formation under exposure to sucrose $3 \%$ and $0.75 \mathrm{ppmF}$.

\begin{tabular}{lcc}
\hline Variables & $\begin{array}{c}3 \text { days } \\
(n=8)\end{array}$ & $\begin{array}{c}9 \text { days } \\
(n=6)\end{array}$ \\
\hline Total cells $\left(\times 10^{8}\right)$ & $\begin{array}{c}0.9 \pm 0.1^{\mathrm{b}} \\
(n=7)\end{array}$ & $1.3 \pm 0.3^{\mathrm{a}}$ \\
L. casei $\left(\times 10^{8}\right)$ & $\begin{array}{c}0.9 \pm 0.1^{\mathrm{b}} \\
(n=7)\end{array}$ & $1.4 \pm 0.3^{\mathrm{a}}$ \\
S. salivarius $\left(\times 10^{5}\right)$ & $\begin{array}{c}1.9 \pm 2.2^{\mathrm{a}} \\
(n=7)\end{array}$ & $1.1 \pm 0.3^{\mathrm{a}}$ \\
IML $(\operatorname{vol} \% \times \mu \mathrm{m})$ & $1414 \pm 128^{\mathrm{b}}$ & $2715 \pm 194^{\mathrm{a}}$ \\
LD $(\mu \mathrm{m})$ & $43.5 \pm 6.5^{\mathrm{b}}$ & $80.6 \pm 2.6^{\mathrm{a}}$ \\
\hline
\end{tabular}

Means followed by distinct letters differ statistically $(P<0.05)$.

differences of salivary flow during day/night periods in order to be more consistent with natural conditions and should be adopted in future studies.

Despite the inoculation of slabs with a multispecies suspension of bacteria containing the same number of viable cells for each strain (about $10^{7} \mathrm{CFU} / \mathrm{mL}$ ), L. case $i$ were the bacteria most prevalent in the biofilms $\left(10^{7}-10^{8} \mathrm{CFU} / \mathrm{mL}\right)$. $S$. salivarius were the second most prevalent in biofilms $\left(10^{5} \mathrm{CFU} / \mathrm{mL}\right)$. However, the counts of the other 3 species were below the detection limit. Like Shu et al. [32], A. naeslundii has not been well established in a multispecies in vitro community. It was suggested that one reason for this deficiency in A. naeslundii biofilm colonization might be a result of its low acid-tolerance profile as suggested elsewhere [33-35]. This same feature could also explain the poor colonization of biofilms by S. sanguinis, due to the $\mathrm{pH}$ of the vessels falling in the range of 4.0 to 5.0. Moreover, Harper and Loesche [36] showed that L. casei and S. mutans have greater acid-tolerance than S. sanguinis, S. salivarius, and Actinomyces. However, an intriguing finding was the undetectable counts of $S$. mutans on biofilms. These microorganisms are highly acidogenic and acid-tolerant and their ability to form in vitro biofilms and their cariogenic potential have also been extensively shown by several studies [37-39]. Furthermore, previous research has shown that $S$. mutans utilizes sucrose at a faster rate than S. sanguinis, A. naeslundii, and $L$. casei [40] which could pose some competitive advantage in relation to these strains during the colonization of the biofilm. However, it seems that even these traits were not enough to enable successful competition against the other bacterial strains under the experimental conditions of this present study. In this respect, it has also been discussed that reduced expressions of $g t f \mathrm{~B}$ and $g b p \mathrm{~B}$ genes were found when $S$. mutans was cocultivated in a biofilm with $L$. casei which contributes to enhancing biofilm formation by $L$. casei under an in vitro condition [41]. This, in turn, may provide a greater competitiveness of $L$. casei in relation to S. mutans.

Lactobacilliare resistant to fluoride. Up to $1 \mathrm{mM}$ of $\mathrm{NaF}$ $(19 \mathrm{ppmF})$ was able to reduce the viability of $S$. mutans in a chemostat model but it did not alter the viability of lactobacilli [42]. It was also found that Actinomyces and S. sanguinis are even more sensitive to fluoride than S. mutans. 
Clinically, the long-term use of fluoridated mouthrinses for up to $7 \mathrm{yr}$ decreased the levels of mutans streptococci in saliva without affecting the levels of lactobacilli [43]. Although the fluoride concentration used by these cited studies was higher than what was used in the present study, the previous data might contribute to understanding the predominance of lactobacilli in the biofilm. On the other hand, it has been shown that an increased concentration of fluoride from 0.2 to $1.0 \mathrm{ppm}$ during biofilm growth was able to decrease the viability of $L$. case $i$ in a multispecies biofilm model [44]. Within this same range of fluoride concentration, the lowest counts of $S$. mutans were found only in the presence of $0.2 \mathrm{ppmF}$ and no statistical difference was found for those counts under fluoride concentrations up to $1.0 \mathrm{ppmF}$ [44]. Using the same microbial composition used in this present study, Fontana et al. [20] were able to find expressive counts of $S$. mutans on biofilms even after $8 \mathrm{~d}$ of biofilm growth. However, it is important to note that those biofilms were grown in the presence of $0.25 \mathrm{ppmF}$. Considering these previous findings, the increased fluoride concentrations used in the present study potentially produced an inhibitory effect for $S$. mutans even under a lower concentration than what is considered as antimicrobial [42]. At this time, it is not clear if the undetectable levels of $S$. sanguinis on our multispecies biofilms were also a result of an inhibitory effect of fluoride due to no record by Fontana et al. [20] indicating the range of biofilm colonization by this strain. It is important to emphasize though that the differences between our results and those found by Fontana et al. [20] and Arthur et al. [44] may be related mainly to the distinct experimental conditions among the studies.

Interestingly, in other experiments conducted in our laboratory, up to $10^{6}$ and $10^{4} \mathrm{CFU} / \mathrm{mL}$ of $S$. mutans and $S$. sanguinis, respectively, were found after three days of biofilm formation (unpublished data) under exposure to $0.75 \mathrm{ppmF}$ and 3\% sucrose using the same multispecies microbial model described in this paper. Although these data were not found by the present study (Study 2), we hypothesize that the counts of viable cells found on biofilms produced by this microbial caries model are the result of a microbial ecological selection. That is, the higher acid-tolerance and fluoride resistance of $L$. casei in relation to $S$. mutans $[25,42]$ could explain the lower counts of $S$. mutans on biofilms. Our results might suggest that $S$. mutans were not able to develop an aciduric adaptation under the tested conditions evaluated on the present study. $S$. mutans inability to colonize the biofilms under the conditions described in this paper is still unknown and merits further investigation. The higher acid-tolerance of $L$. casei could also explain the higher counts on biofilms formed in the presence of $5 \%$ sucrose under $0.50 \mathrm{ppmF}$ (Table 1). The lower resting $\mathrm{pH}$ of the caries vessel in 5\% sucrose group might have enhanced the biofilm colonization by these microorganisms. This finding is also reflected in counts of total viable cells as L. casei comprises about $100 \%$ of the viable cells in biofilms. Additionally, a recent study has clarified some bacterial interactions that might occur in dental biofilm. According to Tamura et al. [45], S. salivarius may inhibit $S$. mutans biofilm formation due to an inactivation of a $S$. mutans competencestimulating peptide-dependent biofilm formation. Taking this observation into consideration, it is still possible that this interaction might have taken place in this artificial-mouth model contributing to the decreased viability of S. mutans.

Moreover, the resting $\mathrm{pH}$ of the vessels was below those reported previously [20]. As the acidogenic potential of dental biofilm depends on its microbial composition, a direct comparison of our findings with those of Fontana et al. [20] and Shu et al. [32] must be done with care due to the $\mathrm{d}$ ifferent bacterial isolates used in each study. Other important distinctions between our conditions for biofilm formation and previous studies include fluoride and carbohydrate concentration, length of exposure to carbohydrates, and time of biofilm formation. All these factors contribute to explaining the differences in acidogenic potential and counts of viable cells on biofilms among these different studies.

Therefore, distinct sucrose concentrations did not affect enamel carious lesion development. Our data suggest that the severity of lesions produced by this artificial-mouth model is more affected by fluoride than by sucrose concentration. Lower demineralization was found in the presence of the higher fluoride concentration. Furthermore, an increase in the time of biofilm formation produced greater demineralization. Overall, our data also suggest that the present artificialmouth model is suitable for studying several aspects related to caries lesion development. Additionally, it could be used as a feasible alternative to in vivo and clinical studies.

\section{Conflict of Interests}

The authors declare no conflict of interests.

\section{Acknowledgments}

Thanks are due to NIH/NIDCR Project R21 DE018390-01A2. The funder had no role in study design, data collection and analysis, decision to publish, or preparation of the paper. The authors wish to thank Ms. Sharon Gwinn for the excelent assistance.

\section{References}

[1] R. H. Selwitz, A. I. Ismail, and N. B. Pitts, "Dental caries," The Lancet, vol. 369, no. 9555, pp. 51-59, 2007.

[2] P. D. Marsh, "Are dental diseases examples of ecological catastrophes?” Microbiology, vol. 149, no. 2, pp. 279-294, 2003.

[3] J. D. B. Featherstone, "Dental caries: a dynamic disease process," Australian Dental Journal, vol. 53, no. 3, pp. 286-291, 2008.

[4] C. Dawes, "What is the critical $\mathrm{pH}$ and why does a tooth dissolve in acid?" Journal (Canadian Dental Association), vol. 69, no. 11, pp. 722-724, 2003.

[5] L. M. A. Tenuta and J. A. Cury, "Fluoride: its role in dentistry," Brazilian Oral Research, vol. 24, no. 1, pp. 9-17, 2010.

[6] J. M. B. ten Cate, "The need for antibacterial approaches to improve caries control," Advances in dental research, vol. 21, no. 1, pp. 8-12, 2009.

[7] J. A. Cury and L. M. A. Tenuta, "Enamel remineralization: Controlling the caries disease or treating early caries lesions?" Brazilian Oral Research, vol. 23, no. 1, pp. 23-30, 2009. 
[8] H. C. Margolis and E. C. Moreno, "Physicochemical perspectives on the cariostatic mechanisms of systemic and topical fluorides," Journal of Dental Research, vol. 69, pp. 606-613, 1990.

[9] V. C. Marinho, "Cochrane reviews of randomized trials of fluoride therapies for preventing dental caries," European Archives of Paediatric Dentistry, vol. 10, no. 3, pp. 183-191, 2009.

[10] W. H. Bowen and H. Koo, "Biology of streptococcus mutansderived glucosyltransferases: role in extracellular matrix formation of cariogenic biofilms," Caries Research, vol. 45, no. 1, pp. 69-86, 2011.

[11] G. H. Dibdin and R. P. Shellis, "Physical and biochemical studies of Streptococcus mutans sediments suggest new factors linking the cariogenicity of plaque with its extracellular polysaccharide content," Journal of Dental Research, vol. 67, no. 6, pp. 890-895, 1988.

[12] D. T. Zero, J. van Houte, and J. Russo, “The intra-oral effect on enamel demineralization of extracellular matrix material synthesized from sucrose by Streptococcus mutans," Journal of Dental Research, vol. 65, no. 6, pp. 918-923, 1986.

[13] J. A. Cury, M. A. B. Rebelo, A. A. Del Bel Cury, M. T. V. C. Derbyshire, and C. P. M. Tabchoury, "Biochemical composition and cariogenicity of dental plaque formed in the presence of sucrose or glucose and fructose," Caries Research, vol. 34, no. 6, pp. 491497, 2000.

[14] A. F. Paes Leme, C. M. Bellato, G. Bedi, A. A. Del Bel Cury, H. Koo, and J. A. Cury, "Effects of sucrose on the extracellular matrix of plaque-like biofilm formed in vivo, studied by proteomic analysis," Caries Research, vol. 42, no. 6, pp. 435-443, 2008.

[15] Y. W. Cavalcanti, M. M. Bertolini, W. J. da Silva, A. A. del-BelCury, L. M. A. Tenuta, and J. A. Cury, "A three-species biofilm model for the evaluation of enamel and dentin demineralization," Biofouling, vol. 30, no. 5, pp. 579-588, 2014.

[16] R. A. Giacaman, M. P. Contzen, J. A. Yuri, and C. MunozSandoval, "Anticaries effect of an antioxidant-rich apple concentrate on enamel in an experimental biofilm demineralization model," Journal of Applied Microbiology, vol. 117, no. 3, pp. 846853, 2014

[17] W. Zhao, Q. Xie, A. K. Bedran-Russo, S. Pan, J. Ling, and C. $\mathrm{D}$. $\mathrm{Wu}$, "The preventive effect of grape seed extract on artificial enamel caries progression in a microbial biofilm-induced caries model," Journal of Dentistry, vol. 42, no. 8, pp. 1010-1018, 2014.

[18] S. K. Filoche, K. J. Soma, and C. H. Sissons, "Caries-related plaque microcosm biofilms developed in microplates," Oral Microbiology and Immunology, vol. 22, no. 2, pp. 73-79, 2007.

[19] M. S. Azevedo, F. H. Van De Sande, A. R. Romano, and M. S. Cenci, "Microcosm biofilms originating from children with different caries experience have similar cariogenicity under successive sucrose challenges," Caries Research, vol. 45, no. 6, pp. 510-517, 2011.

[20] M. Fontana, A. Haider, and C. Gonzales-Cabezas, "Caries lesion development and biofilm composition response to varying demineralization times and sucrose exposures," Biofilms, vol. 1, pp. 229-237, 2004.

[21] A. T. Hara, M. Ando, C. González-Cabezas, J. A. Cury, M. C. Serra, and D. T. Zero, "Protective effect of the dental pellicle against erosive challenges in situ," Journal of Dental Research, vol. 85, no. 7, pp. 612-616, 2006.

[22] F. Lippert, R. J. M. Lynch, G. J. Eckert, S. A. Kelly, A. T. Hara, and D. T. Zero, "In situ fluoride response of caries lesions with diffe rent mineral distributions at baseline," Caries Research, vol. 45, no. 1, pp. 47-55, 2011.
[23] M. Fontana, A. J. Dunipace, R. L. Gregory et al., "An in vitro microbial model for studying secondary caries formation," Caries Research, vol. 30, no. 2, pp. 112-118, 1996.

[24] B. Guggenheim, E. Giertsen, P. Schüpbach, and S. Shapiro, "Validation of an in vitro biofilm model of supragingival plaque," Journal of Dental Research, vol. 80, no. 1, pp. 363-370, 2001.

[25] M. Ando, M. H. van der Veen, B. R. Schemehorn, and G. K. Stookey, "Comparative study to quantify demineralized enamel in deciduous and permanent teeth using laser- and lightinduced fluorescence techniques," Caries Research, vol. 35, no. 6, pp. 464-470, 2001.

[26] J. M. Ten Cate, "Current concepts on the theories of the mechanism of action of fluoride," Acta Odontologica Scandinavica, vol. 57, no. 6, pp. 325-329, 1999.

[27] C. P. Aires, C. P. M. Tabchoury, A. A. Del Bel Cury, H. Koo, and J. A. Cury, "Effect of sucrose concentration on dental biofilm formed in situ and on enamel demineralization," Caries Research, vol. 40, no. 1, pp. 28-32, 2005.

[28] A. Tehrani, F. Brudevold, F. Attarzadeh, J. van Houte, and J. Russo, "Enamel demineralization by mouthrinses containing different concentrations of sucrose," Journal of Dental Research, vol. 62, no. 12, pp. 1216-1217, 1983.

[29] B. Øgaard, G. Rølla, and J. Arends, "Orthodontic appliances and enamel demineralization. Part 1. Lesion development," The American Journal of Orthodontics and Dentofacial Orthopedics, vol. 94, no. 1, pp. 68-73, 1988.

[30] B. N. Ullsfoss, B. Ogaard, J. Arends, J. Ruben, G. Rölla, and J. Afseth, "Effect of a combined chlorhexidine and $\mathrm{NaF}$ mouthrinse: an in vivo human caries model study," Scandinavian journal of dental research, vol. 102, no. 2, pp. 109-112, 1994.

[31] O. Fejerskov, B. Nyvad, and M. J. Larsen, "Human experimental caries models: intra-oral environmental variability," Advances in Dental Research, vol. 8, no. 2, pp. 134-143, 1994.

[32] M. Shu, L. Wong, J. H. Miller, and C. H. Sissons, "Development of multi-species consortia biofilms of oral bacteria as an enamel and root caries model system," Archives of Oral Biology, vol. 45, no. 1, pp. 27-40, 2000.

[33] G. R. Bender and R. E. Marquis, "Membrane ATPases and acid tolerance of Actinomyces viscosus and Lactobacillus casei," Applied and Environmental Microbiology, vol. 53, no. 9, pp. 2124-2128, 1987.

[34] D. J. Bradshaw, A. S. McKee, and P. D. Marsh, "Effects of carbohydrate pulses and $\mathrm{pH}$ on population shifts within oral microbial communities in vitro.," Journal of Dental Research, vol. 68, no. 9, pp. 1298-1302, 1989.

[35] D. J. Bradshaw and P. D. Marsh, "Analysis of pH-driven disruption of oral microbial communities in vitro," Caries Research, vol. 32, no. 6, pp. 456-462, 1998.

[36] D. S. Harper and W. J. Loesche, "Growth and acid tolerance of human dental plaque bacteria," Archives of Oral Biology, vol. 29, no. 10, pp. 843-848, 1984.

[37] H. Koo, J. Xiao, M. I. Klein, and J. G. Jeon, "Exopolysaccharides produced by Streptococcus mutans glucosyltransferases modulate the establishment of microcolonies within multispecies biofilms," Journal of Bacteriology, vol. 192, no. 12, pp. 3024-3032, 2010.

[38] R. M. Murata, L. S. Branco-de-Almeida, E. M. Franco et al., "Inhibition of Streptococcus mutans biofilm accumulation and development of dental caries in vivo by 7-epiclusianone and fluoride," Biofouling, vol. 26, no. 7, pp. 865-872, 2010. 
[39] J.-G. Jeon, S. Pandit, J. Xiao et al., "Influences of transtrans farnesol, a membranetargeting sesquiterpenoid, on Streptococcus mutans physiology and survival within mixedspecies oral biofilms," International Journal of Oral Science, vol. 3, no. 2, pp. 98-106, 2011.

[40] G. E. Minah and W. J. Loesche, "Sucrose metabolism in resting cell suspensions of caries associated and non caries associated dental plaque," Infection and Immunity, vol. 17, no. 1, pp. 43-54, 1977.

[41] Z. T. Wen, D. Yates, S.-J. Ahn, and R. A. Burne, "Biofilm formation and virulence expression by Streptococcus mutans are altered when grown in dual-species model," BMC Microbiology, vol. 10, article 111, 2010.

[42] D. J. Bradshaw, A. S. McKee, and P. D. Marsh, "Prevention of population shifts in oral microbial communities in vitro by low fluoride concentrations," Journal of Dental Research, vol. 69, no. 2, pp. 436-441, 1990.

[43] A. Yoshihara, S. Sakuma, S. Kobayashi, and H. Miyazaki, "Antimicrobial effect of fluoride mouthrinse on mutans streptococci and lactobacilli in saliva," Pediatric Dentistry, vol. 23, no. 2, pp. 113-117, 2001.

[44] R. A. Arthur, R. A. Waeiss, A. T. Hara, F. Lippert, G. J. Eckert, and D. T. Zero, "A defined-multispecies microbial model for studying enamel caries development," Caries Research, vol. 47, no. 4, pp. 318-324, 2013.

[45] S. Tamura, H. Yonezawa, M. Motegi et al., "Inhibiting effects of Streptococcus salivarius on competence-stimulating peptidedependent biofilm formation by Streptococcus mutans," Oral Microbiology and Immunology, vol. 24, no. 2, pp. 152-161, 2009. 


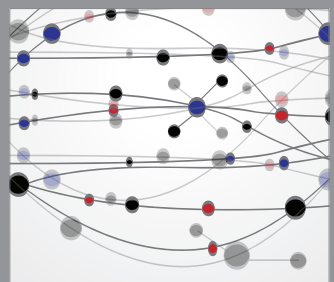

The Scientific World Journal
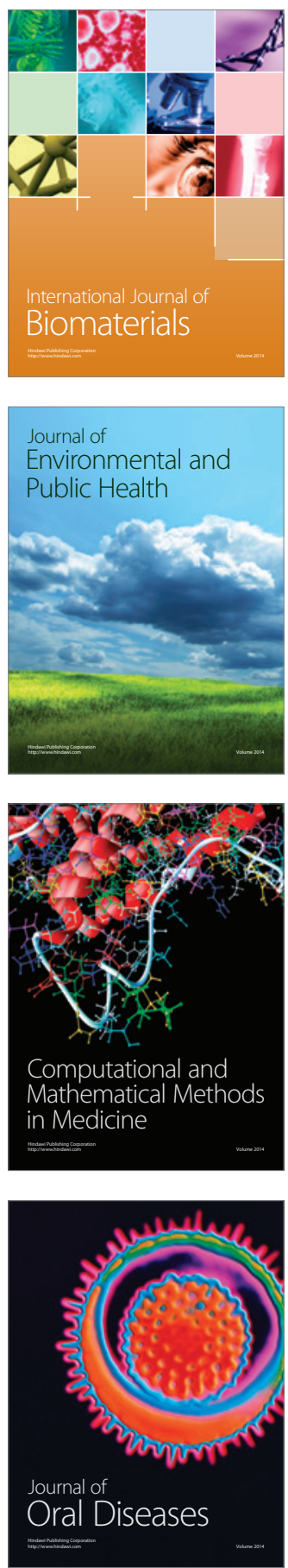
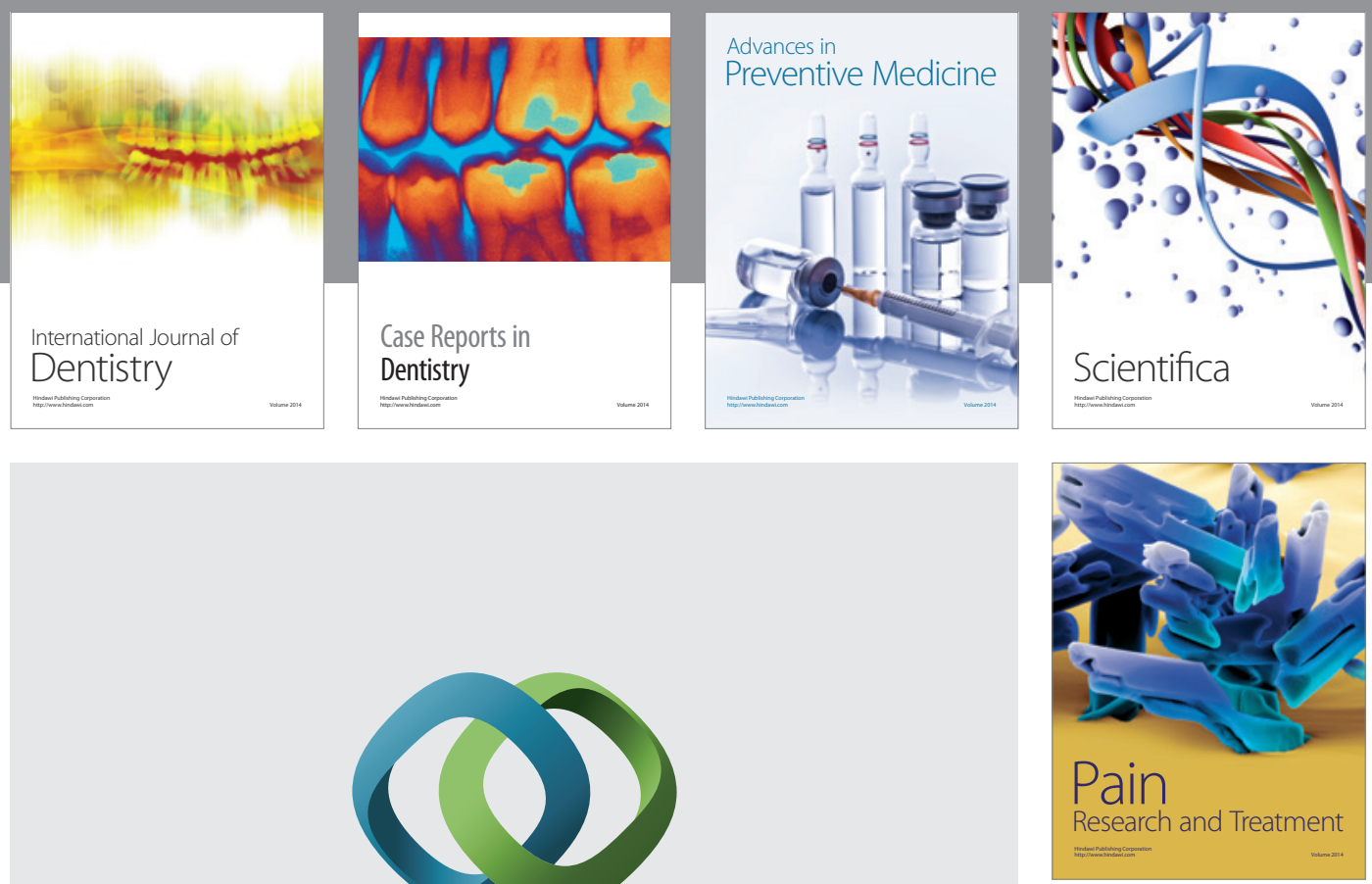

\section{Hindawi}

Submit your manuscripts at

http://www.hindawi.com
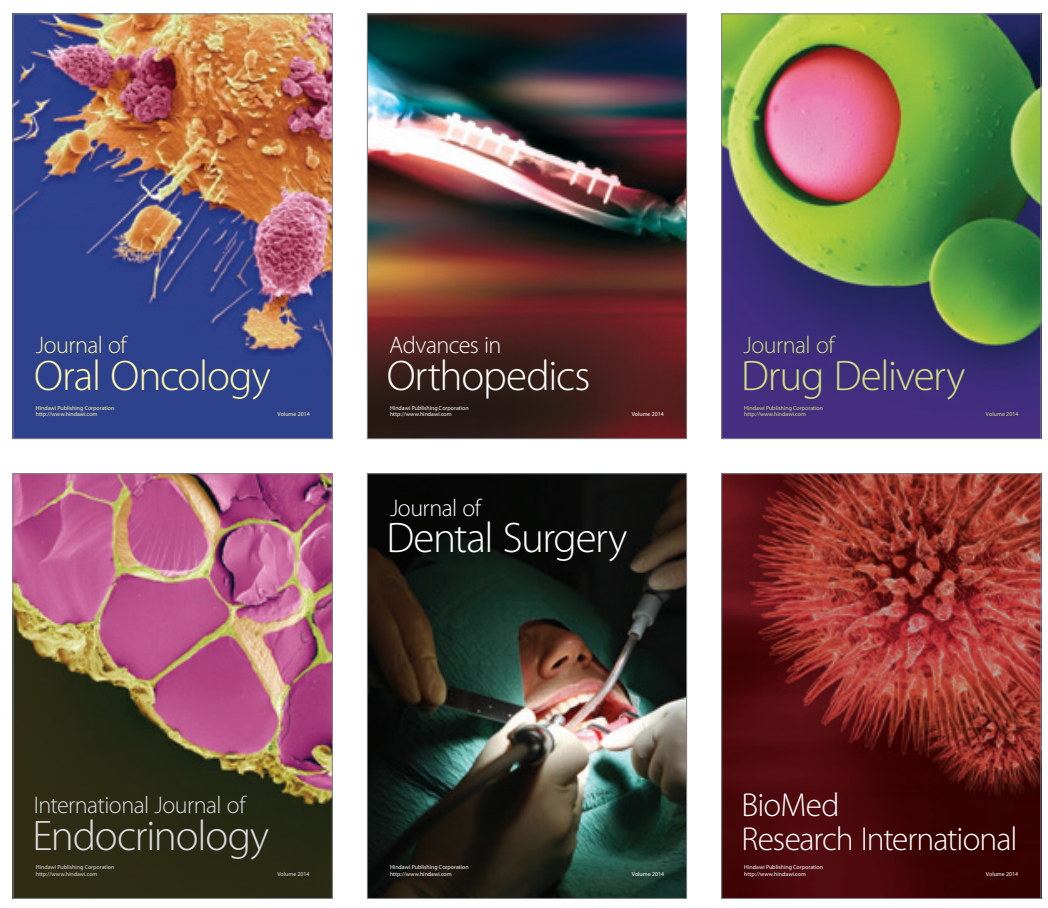

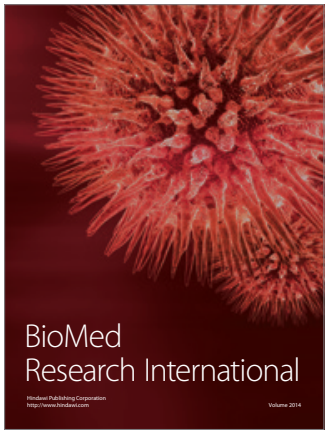

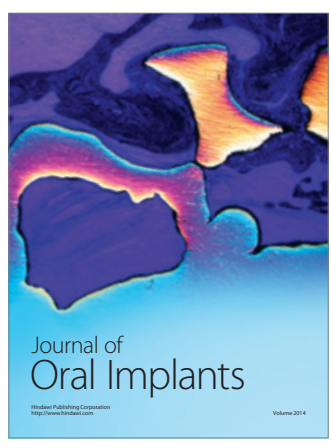
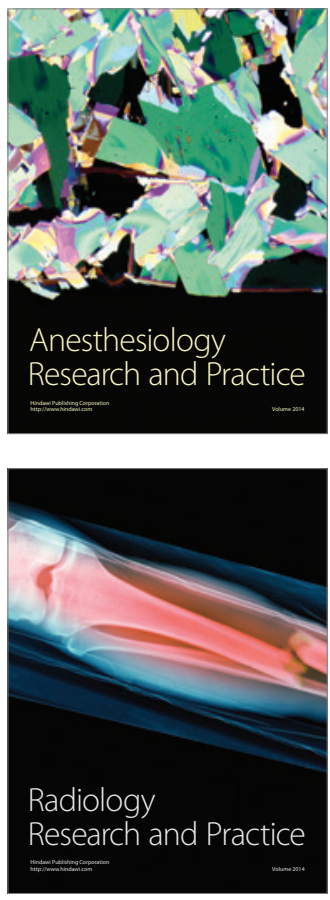